Gut, 1978, 19, 50-55

\title{
Hyposplenism in inflammatory bowel disease
}

\author{
F. P. RYAN, R. C. SMART, C. D. HOLDSWORTH, AND F. E. PRESTON \\ From the Departments of Medicine, Medical Physics, and Haematology, The Royal Infirmary, \\ Sheffield
}

SUMmARY Splenic function was assessed in 35 patients with ulcerative colitis and 20 patients with Crohn's disease. Hyposplenism was diagnosed if there were Howell-Jolly bodies in the peripheral blood film or if there was prolongation of clearance from the peripheral blood of injected ${ }^{51} \mathrm{Cr}$ labelled heat-damaged red blood cells. Thirteen of the patients with ulcerative colitis had hyposplenism as compared with only one patient with Crohn's disease. Conversely, heat-damaged red cell clearance values faster than the normal range were found in six out of the 20 patients with Crohn's disease. Four patients with hyposplenism and ulcerative colitis developed life-threatening septicaemia in the early postcolectomy period, two of these being further complicated by disseminated intravascular coagulation.

Hyposplenism is the functional state that exists after splenectomy in man and it is characterised by the appearance of Howell-Jolly bodies, Pappenheimer bodies, spherocytes, target cells, and bizarre poikilocytes in the peripheral blood film. Hyposplenism may occur spontaneously in such conditions as coeliac disease and dermatitis herpetiformis where the causative mechanisms are uncertain (Marsh and Stewart, 1970; Pettit et al., 1972). In a preliminary report (Ryan et al., 1974) we described for the first time the association in three patients of hyposplenism with ulcerative colitis, an association since confirmed by other authors (Ardeman and Bevan, 1974; Goodyear and Forster, 1974; Wardrop et al., 1975). This paper presents the results of a systematic study into splenic function in inflammatory bowel disease.

\section{Methods}

Thirty-five patients with ulcerative colitis and 20 patients with Crohn's disease were investigated. The diagnosis was based on currently accepted criteria which included clinical features, sigmoidoscopic findings, barium studies, and histology of rectal biopsy material, (Lennard-Jones, 1970; Morson and Dawson, 1972). The diagnosis was confirmed by detailed gross and histological examination of the whole colon in 13 patients with ulcerative colitis and nine patients with Crohn's disease who subsequently came to colectomy. There remains the possibility of

Received for publication 29 April 1977 incorrect classification of the colonic disease in the 22 patients with 'ulcerative colitis' who have not yet come to colectomy and, indeed, two patients initially thought to have ulcerative colitis were found after colectomy to have Crohn's disease and are included in the Crohn's series. We think it less likely that any of our patients diagnosed as Crohn's disease are incorrectly classified.

Patients for study were selected to include different patterns of bowel involvement. The series with ulcerative colitis therefore included patients with both distal and more extensive colonic involvement, while the series with Crohn's disease included patients with ileal disease alone, mixed ileocolonic disease, or solely colonic involvement.

Each patient had serial blood films stained by the Leishman method and examined for the presence of Howell-Jolly bodies, target cells, and other features of hyposplenism. Blood films were also stained with Nile-blue sulphate for the presence of Heinz bodies to exclude drug-induced haemolytic anaemias with particular reference to sulphasalazine, because in some respects this blood film may resemble that found in hyposplenism. The differential leucocyte and platelet counts were assessed simultaneously.

With the exception of one patient with ulcerative colitis, all the patients and 10 normal controls were tested for their ability to clear the peripheral blood of ${ }^{51} \mathrm{Cr}$-labelled heat-damaged red blood cells using a slight modification of the method described by Marsh et al. (1966). Autologous red blood cells were labelled with $150 \mu \mathrm{Ci}{ }^{51} \mathrm{Cr}$ and damaged by heating for 30 minutes at $49.5 \pm 0.5^{\circ} \mathrm{C}$. The labelled cells 
were reinjected intravenously and blood samples taken at $2 \cdot 5,5,10,15,20,30,40,50$, and 60 minutes, with extra samples at two to three hours in some patients. The cells were then haemolysed by the addition of saponin and the radioactivity counted in an automatic well-scintillation counter. The results were fitted by a computer to a double exponential function using a function minimisation programme (Powell, 1964) and the clearance half time, $T_{1}$, and its $95 \%$ confidence limits determined. In the 10 normal controls the $T_{1}$ range was 9.0 to 17.5 minutes, which accords well with the previously reported control range of 10 to 16 minutes (Marsh et al., 1966). The radioactivity over the liver and spleen was continuously recorded for one hour after injection by placing two collimated scintillation counters over these organs. In the majority of patients a posterior rectilinear scan of the spleen was obtained at the end of the study.

All patients were subjected to a careful clinical scrutiny and follow-up to assess the relationship between abnormalities of splenic function and the clinical severity of the bowel disease. Laboratory assessment included standard liver function tests, serum proteins, and electrophoresis, and serum B12 and red cell folate estimations.

Crosby capsule biopsies of the jejunum were carried out in four patients with ulcerative colitis and severe hyposplenism to rule out a concomitant coeliac disease.

\section{Results}

These are summarised in Tables 1 and 2.

\section{RED CELL FILMS}

Each patient had a minimum of three normal blood films after the initial presentation with his bowel condition. Seven patients with ulcerative colitis subsequently developed Howell-Jolly bodies in their blood films. Of the patients with Crohn's disease only one case with extensive Crohn's colitis developed
Howell-Jolly bodies in the blood film. Three further patients with ulcerative colitis developed less specific changes in their blood films, such as burr cells and schistocytes, and in the light of simultaneous red cell clearance tests were found to have lesser degrees of hyposplenism.

All the patients who developed Howell-Jolly bodies in their blood films had at the time severe and extensive colitis (Tables 1 and 2). In five patients the Howell-Jolly bodies first made their appearance during a severe relapse of the ulcerative colitis, the blood films remaining abnormal for a period of weeks. These returned to normal in four of the patientsin two after pan-proctocolectomy and in the other two after medically-induced remission. The fifth patient died after colectomy. Two patients with ulcerative colitis and the one patient with Crohn's disease developed Howell-Jolly bodies during a period of prolonged activity of their disease and in these cases the blood film has remained abnormal over a period of observation extending from one to three years (patients 3, 4 and 14, Table 2).

\section{${ }^{51}$ CR-LABELLED HEAT-DAMAGED RED CELL CLEARANCE}

The results of this study are shown in Fig. 1. Each $T_{\frac{1}{2}}$ value is represented together with the $95 \%$ confidence limits.

Of the patients with ulcerative colitis, 10 were frankly abnormal when compared with the controls, their $T_{1}$ values ranging from $20 \cdot 4$ to $>171$ minutes. Three other patients, who were not examined by the isotopic clearance test at that time, had hyposplenism on the basis of their blood films, making a total of 13 with hyposplenism out of 36 patients with ulcerative colitis. Patients with Howell-Jolly bodies at the time of the damaged red cell clearance study had the most abnormal results, the $T_{\frac{1}{2}}$ value always exceeding 60 minutes. This again is in close agreement with the $T_{1}$ value of $>50$ minutes previously found to be associated with Howell-Jolly bodies in the blood film (Marsh and Stewart, 1970).

Table 1 Summary of abnormal blood films and $T_{\frac{1}{2}}$ clearance values in relation to type and extent of bowel disease

\begin{tabular}{|c|c|c|c|c|c|}
\hline Disease & Extent & Total no. & No. with $\mathrm{H}-\mathrm{J}$ bodies & No. with long $T_{\frac{1}{1}}$ & No. with short $T_{\frac{1}{1}}$ \\
\hline \multirow[t]{2}{*}{ Ulcerative colitis } & $\begin{array}{l}\text { Extensive } \\
\text { Distal }\end{array}$ & $\begin{array}{l}24 \\
11\end{array}$ & $\begin{array}{l}7 \\
0\end{array}$ & $\begin{array}{r}10 \\
0\end{array}$ & $\begin{array}{l}1 \\
0\end{array}$ \\
\hline & Total & $\overline{35}$ & $\overline{7}$ & $\overline{10}$ & $\overline{1}$ \\
\hline \multirow[t]{2}{*}{ Crohn's disease } & $\begin{array}{l}\text { Ileal } \\
\text { Ileocolonic } \\
\text { Colonic }\end{array}$ & $\begin{array}{r}5 \\
8 \\
7 \\
-\end{array}$ & $\begin{array}{l}0 \\
0 \\
1 \\
\end{array}$ & $\begin{array}{l}0 \\
0 \\
1 \\
-\end{array}$ & $\begin{array}{l}5 \\
1 \\
0 \\
-\end{array}$ \\
\hline & Total & 20 & 1 & $\overline{1}$ & 6 \\
\hline
\end{tabular}

Extensive ulcerative colitis: extending proximally beyond splenic flexure. Distal ulcerative colitis: involving proximally no further than the splenic flexure. H-J bodies: Howell-Jolly bodies. $\mathrm{T}_{\frac{1}{2}}$ : half time to clear peripheral blood of autologous ${ }^{\mathrm{s}} \mathrm{Cr}$-labelled heat-damaged red blood cells. 
Table 2 Correlation of abnormal splenic function with clinical course and severity of bowel disease in 14 patients with Howell-Jolly bodies or prolonged clearance of heat-damaged ${ }^{51}$ Cr-labelled red blood cells (prolonged $T_{\ddagger}$ )

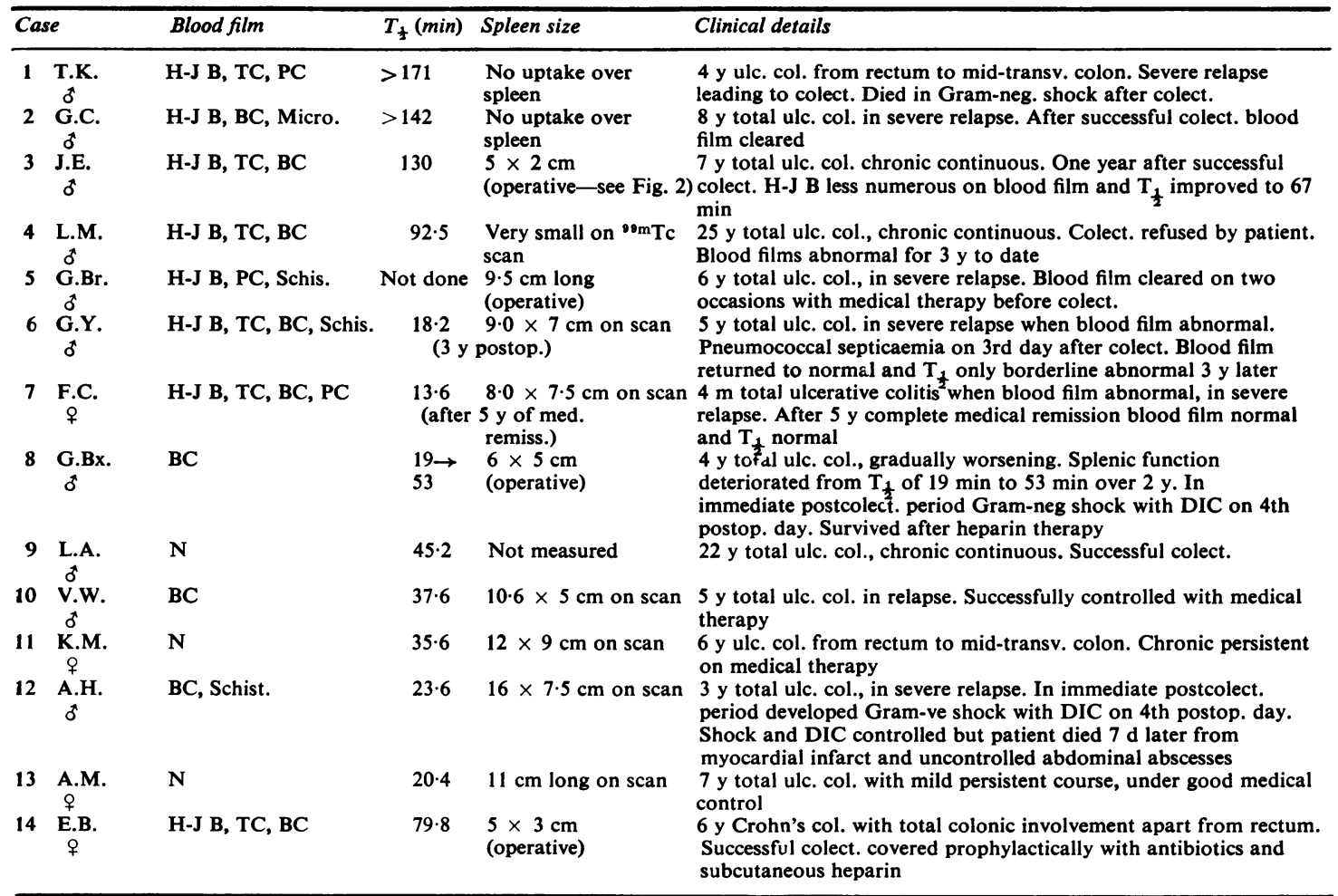

H-J B: Howell-Jolly bodies. TC: target cells. BC: burr cells. Micro.: microspherocytes. Schis.: schistocytes. PC: Pappenheimer cells. $\mathrm{N}$ : normal. DIC-disseminated intravascular coagulation. Normal $T_{\frac{1}{2}} 9-17.5$ minutes. Normal splenic size on scanning $8.5-13.5 \mathrm{~cm}$ (mean $10.6 \mathrm{~cm}) \times 5.5-10.5 \mathrm{~cm}($ mean $7.7 \mathrm{~cm}$ ).

Six patients had $T_{\frac{1}{2}}$ values which, although prolonged, were less than 60 minutes and these patients did not have Howell-Jolly bodies in the blood films. In these cases hyposplenism could be diagnosed only by using the isotopic technique. Four other patients had borderline abnormal results, with $T_{1}$ values longer than the normal range but with $95 \%$ confidence limits overlapping. One of these had recovered from a previous severe hyposplenism and another went on to develop severe hyposplenism two years later.

Like the abnormal red cell films, abnormality of damaged red cell clearance was closely correlated with the patient's clinical state (Tables 1 and 2). Only patients with extensive colitis had prolonged clearance values, no patient with distal colitis having hyposplenism. Of the 10 patients who were abnormal by this test only two (cases 11 and 13) with mild abnormality were under satisfactory medical control of their colitis at the time of testing. Five patients were in severe relapse and the three remaining patients were suffering from persistently active colitis when tested. The tendency for hyposplenism to occur in patients with severe colitis was further exemplified by the fact that eight out of the 13 ulcerative colitic patients affected needed panproctocolectomy, with one other patient refusing operation, while only five of the 23 patients with normal splenic function have required colectomy.

In several patients splenic function fluctuated with the disease state. For example, if the colitis worsened then splenic function also was observed to deteriorate, as in case 8 . In case 4 where there has been a persistently active colitis the hyposplenism has also persisted for three years and in cases 3 and 14 hyposplenism persisted for two years and six months respectively preoperatively while the colitis was persistently active. An improvement in case 3 with a fall in $T_{1}$ from 130 to 67 minutes occurred during the first postoperative year, while in case 6 there was a marked improvement from severe hyposplenism to borderline abnormal three years after colectomy. In 


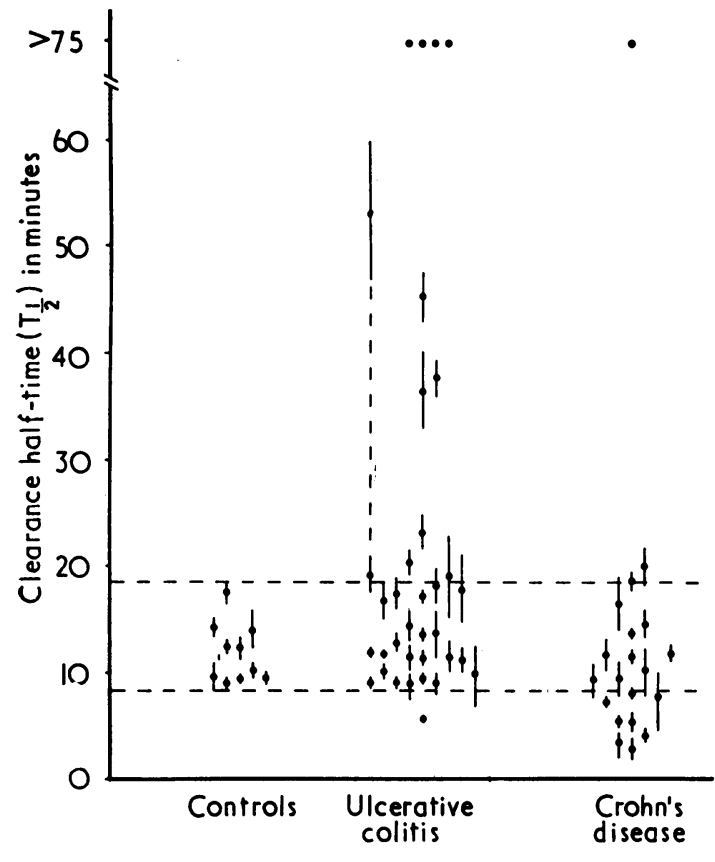

Fig. 1 The results of ${ }^{51} \mathrm{Cr}$-labelled heat-damaged red cell clearance studies in 10 controls, 36 patients with ulcerative colitis, and 20 patients with Crohn's disease. The clearance half time $\left(T_{1}\right)$ for each control and patient is expressed together with the $95 \%$ confidence limits.

case 7 there was a recovery from severe hyposplenism to a normal $T_{ \pm}$value after five years of complete medical remission.

The administration of steroids tended to improve hyposplenism if it resulted in a medical remission. Case 5, who objected to the isotope study on religious grounds, suffered two severe relapses while being prepared for surgery. In each relapse the blood picture was that of severe hyposplenism, evidence for which disappeared on both occasions in response to high doses of steroids. Of the 13 patients with hyposplenism and ulcerative colitis a surprisingly high number, seven, had been intolerant of the drug sulphasalazine as compared with none of the group with normal splenic function. Perhaps this is a reflection of the more frequent and severe relapses which occur in patients not able to have the benefit of continuous sulphasalazine therapy.

The one patient with Crohn's disease who had Howell-Jolly bodies in the blood film also had a frankly prolonged $T_{\frac{1}{2}}$ of 79.8 minutes. This patient with extensive Crohn's colitis also suffered from hypopituitarism and had strongly positive antithyroid antibodies. Two other patients with Crohn's colitis had borderline prolonged $T_{\frac{1}{2}}$ values. It was surprising to find that six out of the 20 patients had $T_{\frac{1}{2}}$ values significantly below the normal range. A possible relationship again appeared to exist between the site of involvement and clearance value, in that five of these six patients with Crohn's disease had isolated ileal disease.

\section{SPLENIC SIZE}

In those patients developing hyposplenism in parallel with a chronic colitis the spleen was very small (cases, $3,4,8$, and 14). In these cases there was no uptake over the spleen during the isotopic test so that the organ could not be scanned. In three cases the vestigial spleen was measured at colectomy (Fig. 2), being visualised on a ${ }^{99 \mathrm{~m}} \mathrm{Tc}$ sulphur colloid scan in the fourth. In patients developing lesser degrees of hyposplenism, or severe hyposplenism during a relapse of their colitis, splenic size tended more towards the normal and could even be increased despite apparent lack of function (case 12).

\section{RELATIONSHIP WITH OTHER FEATURES}

The platelet count rose in four patients when hyposplenism developed acutely during a severe relapse of colitis, with counts as high as $1,000 \times 10^{9} / 1$ (normal range $\left.150-350 \times 10^{9} / 1\right)$. The platelet count returned

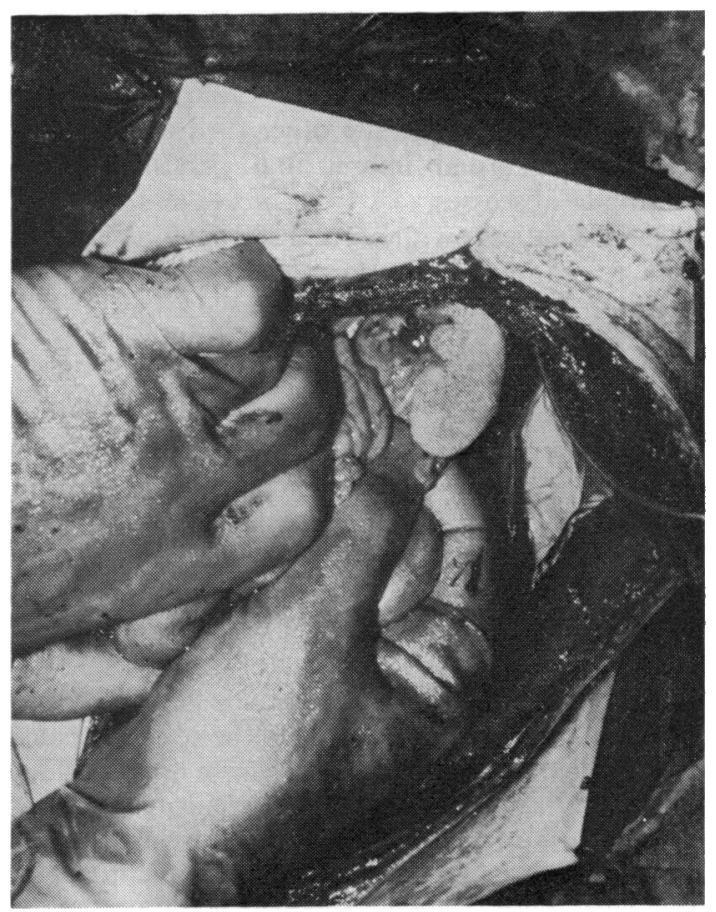

Fig. 2 Case 3. The spleen at operation. The small size $(5 \times 2 \mathrm{~cm})$ can be gauged in relation to the surgeon's thumb. 
to normal over a period of two to four weeks in these patients in parallel with improvement in their condition and clearing of the hyposplenic blood film. In the patients with prolonged hyposplenism and persistently active colitis the platelet count was normal.

All four Crosby capsule biopsies of jejunum in patients with severe hyposplenism were normal (cases 3, 4, 8, and 14). There was no detectable relationship between abnormality of the spleen and liver function, serum proteins, serum B12, or red cell folate levels.

\section{CLINICAL SEQUELAE}

In four of the eight patients with hyposplenism and ulcerative colitis who have had a panproctocolectomy complications have followed a disturbingly similar course. One patient developed pneumococcal septicaemia on the third postoperative day (case 6) while three other patients developed a severe state of shock in the immediate postcolectomy period, with the clinical picture of Gram-negative septicaemia (cases 1, 8, and 12). One of these three patients died in persistent shock on the third postoperative day, while the remaining two developed a florid picture of disseminated intravascular coagulation on the fourth postoperative day in spite of prior antibiotics and intensive care. With the addition of heparin to their therapy each patient fully recovered from the shock and disseminated intravascular coagulation, one patient surviving while the other died a week later from a myocardial infarct and persistent intraabdominal abscesses.

The five patients with normal splenic function who came to panproctocolectomy recovered from the operation without septicaemic complications.

\section{Discussion}

In this study hyposplenism was found to be a common complication of ulcerative colitis, occurring only in those patients with extensive colonic involvement and suffering either a severe relapse or a persistently active course. It was found that careful screening of the blood film alone was not sufficient to detect hyposplenism, Howell-Jolly bodies being found only in the more severely affected patientsthat is, seven out of 13 patients in the series. Because many patients with hyposplenism have normal blood films and also because hyposplenism is often transient, occurring in the final severe relapse before colectomy, it is perhaps understandable that the frequency with which hyposplenism occurs in ulcerative colitis has not been hitherto appreciated.

The technique of measuring the rate of clearance of ${ }^{51} \mathrm{Cr}$-labelled heat-damaged red cells from the circulation was found to be very sensitive and useful, demonstrating that there is a wide range of abnormality of splenic function in these patients. The basic technique was found to be without complication and caused little distress, being possible even in a severely ill patient when the blood samples could be taken by the bedside, the use of surface counters being omitted. Additional advantages of this technique were the estimation of splenic size on the scan, and the ability to measure changes in splenic function with time.

In the patients with Crohn's disease, although only 20 patients were tested, there appeared to be a correlation between splenic function and site of the disease. Five out of the six patients with fast clearances had isolated ileal involvement. Two patients with borderline prolonged clearance values and the one patient with a markedly prolonged clearance value all had isolated colonic Crohn's disease with degrees of colonic involvement that were similar to those in the patients with ulcerative colitis and hyposplenism. However, some care should be taken in interpreting the significance of severe hyposplenism in the one patient with Crohn's disease, as hypopituitarism and possibly autoimmune thyroid disease may have been factors in causing the spleen to atrophy (Sheehan and Summers, 1949; Brownlie et al., 1975). Almost one year after panproctocolectomy this patient's $T_{\frac{1}{1}}$ for removal of damaged cells remains very abnormal at 71 minutes.

Splenic size was greatly reduced in those patients developing severe hyposplenism during a period of prolonged active colitis, but it was normal or even increased in some of the patients with lesser degrees of hyposplenism. Clearly splenic function does not always bear a strict relationship to size and simple splenic scanning would not be a sufficient indicator of splenic function in this sort of patient. This is discussed more fully elsewhere (Smart et al., 1977).

The changes in the platelet count were similar to those usually associated with splenectomy in man, with marked rises in the platelet count occurring in some of the patients after acute loss of splenic function. Although increased platelet counts were also observed in some patients with ulcerative colitis and normal splenic function, hyposplenism is likely to be one factor contributing to the thrombocytosis known to be associated with inflammatory bowel disease (Morowitz et al., 1968).

There appears to be an important association between hyposplenism in ulcerative colitis and septicaemia in the immediate postcolectomy period. It may be relevant that one of the four patients reported by Ardeman and Bevan (1974) died from Gram-negative shock in the postcolectomy period (personal communication). One of our own patients 
(case 6) suffered pneumococcal septicaemia, wellknown to be associated with splenectomy, on the third day after colectomy. The recurring pattern in the other three patients - with the clinical diagnosis of Gram-negative septicaemia in the immediate postoperative period and disseminated intravascular coagulation on the fourth day in two of themwould appear to indicate that these patients were especially susceptible to these complications. The presentation of the disseminated intravascular coagulation and the clinical and pathological features of these cases have been described elsewhere (Ryan et al., 1977). While three of these patients were ill and in a relapse before surgery, one (case 8 ) had an elective procedure and had been in good general health before surgery. It is relevant that hyposplenism has previously been associated with pneumococcal septicaemia and disseminated intravascular coagulation (Whitaker, 1969).

The cause of hyposplenism in ulcerative colitis, as in coeliac disease, remains uncertain. Folate deficiency, thought by Marsh and Stewart (1970) to be a possibility in coeliac disease, seems very unlikely. Our own tests for disseminated intravascular coagulation at the time of onset of hyposplenism have been repeatedly negative, ruling out involvement of the splenic circulation with disseminated intravascular coagulation as the cause. The fact that splenic function can improve after severe hyposplenism and also the fact that the scan shows no filling defects in those patients with lesser degrees of hyposplenism probably rules out infarction of the spleen. The most tenable possibilities seem to be either involvement as part of a severe lymphoreticular depression (McCarthy et al., 1966) or possibly impairment of the splenic microcirculation. The parallel course of the colitis and splenic function might imply that the hyposplenism was accompanied by impaired ability of the patient's immune mechanisms to control the bowel inflammation, thereby explaining the tendency for hyposplenism to be found in the final relapse before surgery and also the observation that patients with severe hyposplenism and small spleens tended to have a persistently active colitis without remission. On the other hand, removal of the diseased colon clearly removed the factor depressing the spleen as some recovery of function did then occur.

In coeliac disease hyposplenism is accompanied by a generalised lymphoreticular atrophy (McCarthy $e t$ al., 1966) and interim results of immunological studies on our own patients with hyposplenism certainly indicate impaired immunity. Such a disturbance of immunity or reticuloendothelial function may be the crucial factor in the susceptibility to lifethreatening infections after colectomy in these patients.

We are pleased to acknowledge the co-operation we received from Dr S. Ardeman and Dr G. Bevan of Edgware General Hospital, who kindly allowed us to see full clinical details of the four patients with hyposplenism and ulcerative colitis which they reported in the Lancet in 1974, and for their permission to refer to this in our paper.

\section{References}

Ardeman, S., and Bevan, G. (1974). Hyposplenism and ulcerative colitis. Lancet, $2,588$.

Brownlie, B. E. W., Hamer, J. W., Cook, H. B., and Hamwood, S. M. (1975). Thyrotoxicosis associated with splenic atrophy. Lancet, 2, 1046-1047.

Goodyear, M. D. E., and Forster, D. C. (1974). Hyposplenism in ulcerative colitis. Lancet, 2, 658.

Lennard-Jones, J. E. (1970). Crohn's disease, In Modern Trends in Gastroenterology 4, pp. 273-308. Edited by B. Creamer and W. I. Card. Butterworths: London.

McCarthy, C. F., Fraser, I. D., Evans, K. T., and Read, A. E. (1966). Lymphoreticular dysfunction in idiopathic steatorrhoea. Gut, 7, 140-148.

Marsh, G. W., Lewis, S. M., and Szur, L. (1966). The use of ${ }^{51} \mathrm{Cr}$-labelled heat-damaged red cells to study splenic function. British Journal of Haematology, 12, 161-166.

Marsh, G. W., and Stewart, J. S. (1970). Splenic function in adult coeliac disease. British Journal of Haematology, 19, 445-457.

Morson, B. C., and Dawson, I. M. P. (1972). Gastrointestinal Pathology. Blackwell: Oxford.

Morowitz, D. A., Allen, L. W., and Kirsner, J. B. (1968). Thrombocytosis in chronic inflammatory bowel disease. Annals of Internal Medicine, 68, 1013-1021.

Pettit, J. E., Hoffbrand, A. V., Seah, P. P., and Fry, L. (1972). Splenic atrophy in dermatitis herpertiformis. British Medical Journal, 2, 438-440.

Powell, M. J. D. (1964). An efficient method for finding the minimum of a function of several variables without calculating derivatives. Computer Journal, 7, 155-162.

Ryan, F. P., Smart, R. C., Preston, F. E., and Holdsworth, C. D. (1974). Hyposplenism in ulcerative colitis. Lancet, 2, 318-320.

Ryan, F. P., Timperley, W. R., Preston, F. E., and Holdsworth, C. D. (1977). Cerebral involvement with disseminated intravascular coagulation in intestinal disease. Journal of Clinical Pathology, 30, 551-555.

Sheehan, H. L., and Summers, V. K. (1949). The syndrome of hypopituitarism. Quarterly Journal of Medicine, 18, 319378.

Smart, R. C., Ryan, F. P., Holdsworth, C. D., and Preston, F. E. (1977). Relationship between splenic size and splenic function. Gut, 19, 56-59.

Wardrop, C. A. J., Dagg, J. H., Lee, F. D., Singh, H., Dyet, J. F., and Moffat, A. (1975). Immunological abnormalities in splenic atrophy. Lancet, 2, 4-7.

Whitaker, A. N. (1969). Infection and the spleen: association between hyposplenism, pneumococcal sepsis and disseminated intravascular coagulation. Medical Journal of Australia, 1, 1213-1219. 